This PDF is a selection from a published volume from the National Bureau of Economic Research

Volume Title: International Financial Issues in the Pacific Rim: Global Imbalances, Financial Liberalization, and Exchange Rate Policy (NBER-EASE Volume 17)

Volume Author/Editor: Takatoshi Ito and Andrew K. Rose, editors

Volume Publisher: The University of Chicago Press

Volume ISBN: 0-226-38682-1

Volume URL: http://www.nber.org/books/ito_08-1

Conference Dates: June 22-24, 2006

Publication Date: July 2008

Chapter Title: The Relationship between Openness and Inflation in NIEs and the G7

Chapter Author: Chung-Shu Wu, Jin-Lung Lin

Chapter URL: http://www.nber.org/chapters/c6981

Chapter pages in book: (109 - 137) 


\title{
The Relationship between Openness and Inflation in NIEs and the G7
}

\author{
Chung-Shu Wu and Jin-Lung Lin
}

\subsection{Introduction}

Investigating a sample of 114 countries, Romer (1993) found a significant negative relationship between openness and inflation. For a crosssection data set that covers so many countries, it is difficult for a researcher to understand the economic situation of every country in the sample set. If the set includes some countries that have a special economic structure, the empirical results might be significantly distorted. In this paper, we investigate the relatively familiar economies, such as Newly Industrialized Economies (NIEs) and the G7, to verify the robustness of Romer's findings. Our empirical results show that openness and inflation do not have a regular relationship as stated by Romer (1993).

Romer (1993) interpreted his findings by using the time consistency theory of inflation, which states that in the more open economies the inflation caused by a surprising monetary expansion will be higher. Therefore, the monetary authorities in these countries tend to follow a more conservative policy than those of less open economies. Since this argument has important implications not only on the validity of time consistency policy, but also on economic cooperation and integration, many researchers have followed his footsteps and continue discussing the relationship between openness and inflation. Among them, Lane (1997) built a small open economy model which has a monopolistic distortion and nominal price rigidity in

Chung-Shu Wu is a professor of finance at National Dong Hwa University, and a professor of economics at National Chengchi University and at National Taiwan University. JinLung Lin is a professor of finance at National Dong Hwa University.

The authors thank Peter B. Hendry, Andrew K. Rose, John Simon and the other conference participants for their valuable comments and suggestions. Chih-Ping Fan provided excellent research assistance. 
the nontraded sector to illustrate that the gains at a surprising monetary expansion are lower in a more open economy. In his empirical results, Lane also found a significant inverse relationship between openness and inflation. However, by dividing Romer's sample into four groups of countries according to the indebtedness level, Terra (1998) found a significant negative relationship between openness and inflation only in the severely indebted countries. Moreover, using a variety of measures of the trade-off between output and inflation (the slope of the Phillips curve), Temple (2002) could not find a stable correlation between the trade-off and openness, which cast doubts about the argument raised by Romer (1993).

Although the literature does not reflect a consensus about the relationship between openness and inflation, most derived their results based on a period averaged cross-section data. It is clear that a country's openness or inflation may vary dramatically during a certain period. To represent a country's characteristics by period averaged indexes may not reflect the actual phenomenon. Moreover, traditionally, researchers use the share of imports in GDP or GNP as a proxy for openness. It is quite possible that some countries have a very high imports share because of geographical or other reasons, and have low inflation due to other factors (which may or may not be explained by the time consistency theory). If we include these data into a sample that does not have a regular relationship between openness and inflation, it is very likely for us to find a spurious "significant relationship" result. However, it is not because the theory is right, but because we have not taken into account the problem of extreme value. To compare the empirical results between Romer (1993) and Temple (2002), it can be noted that the difference may result from excluding some countries with special property. ${ }^{1}$ In this paper, we use a panel data set that includes some NIE countries (Hong Kong, Korea, Mexico, Philippines, Singapore, and Taiwan) and the G7 (Canada, France, Germany, Italy, Japan, U.K. and the United States) ${ }^{2}$ to reinvestigate the relationship between openness and inflation. Since the number of countries under investigation is only thirteen, it is relatively easy for us to go through the patterns of openness and inflation of each country. Therefore, we can check the robustness of our empirical results with regard to the extreme value problem. In addition, using the panel data, we can verify the time consistency theory by examining the corollary of the theory that the effect of a monetary expansion on output is smaller in a more open economy.

The rest of the paper is organized as follows. Section 4.2 describes the historical patterns of openness and inflation of NIEs and the G7. Section 4.3 investigates the relationship between openness and inflation using an-

1. Countries with high openness and low inflation, such as Singapore and Lesotho, are not included in the sample set of Temple (2002).

2 . Since we run the time series regression in the latter part of this paper, we select the countries that have a complete quarterly data before 1990 . 
nual panel data. The empirical results of a time series approach to the relationship for each individual country are presented in section 4.4. In section 4.5 we adopt a VAR analysis to examine the impacts of money supply on output in order to check the corollary of Romer's model (1993). Section 4.6 offers some conclusions.

\subsection{Historical Patterns of Openness and Inflation of NIEs and the G7}

The historical patterns of imports (imports/GDP), shares, and the annual growth rate of the GDP deflator of thirteen countries are plotted in figure 4.1 and figure 4.2. From figure 4.1 it can be noticed that some countries such as Canada, Hong Kong, Italy, Korea, the Philippines, Taiwan, and the United States have a significant upward trend for imports shares. However, some countries like Japan, Singapore, and United Kingdom the imports shares do not show an obvious trend. ${ }^{3}$ Nevertheless, to our knowledge, Japan and Singapore have been steadily opening their capital market and restructuring their tariff system. The import shares seemingly cannot appropriately reflect the actual openness conditions for those countries. Moreover, it can be seen from table 4.1 that compared to the $\mathrm{G} 7$ countries, the NIEs have a relatively high imports share. Especially for Hong Kong and Singapore, their periods of averaged import shares are as high as 89.6 percent and 152.2 percent respectively. Since Hong Kong is an international harbor and Singapore is a city country, it is not strange for them to have such high imports shares.

If we compare the openness and inflation in the NIEs, it is easily noticed that Singapore, who has the highest openness but enjoys the lowest inflation, is the standard model that fulfills the argument of time consistency theory. However, there exist some cases that are not satisfied by the theory. Hong Kong has a much higher openness than Taiwan, yet its inflation is higher than Taiwan. If we examine the relationship among the G7 countries, we can find the same phenomena. For some comparisons, they accord with Romer's findings, such as Germany vs. Italy, and Canada vs. France. In contrast, some comparisons do not fit the theory, for example, the United Kingdom vs. the United States, and France vs. Japan. If we compare the two different regions' countries, it is easy to find some Asian countries like Hong Kong and Korea whose openness is higher than most the G7 countries, but also have higher inflation, contradicting the time consistency theory.

There are many reasons to account for the contradiction. For example, it can be seen from table 4.1 that Taiwan has a lower inflation than Hong

3. Different definitions of openness such as exports/GDP share or (exports + imports)/GDP share have a similar pattern. In addition, the empirical results of this paper are robust with regard to the opening definition. 

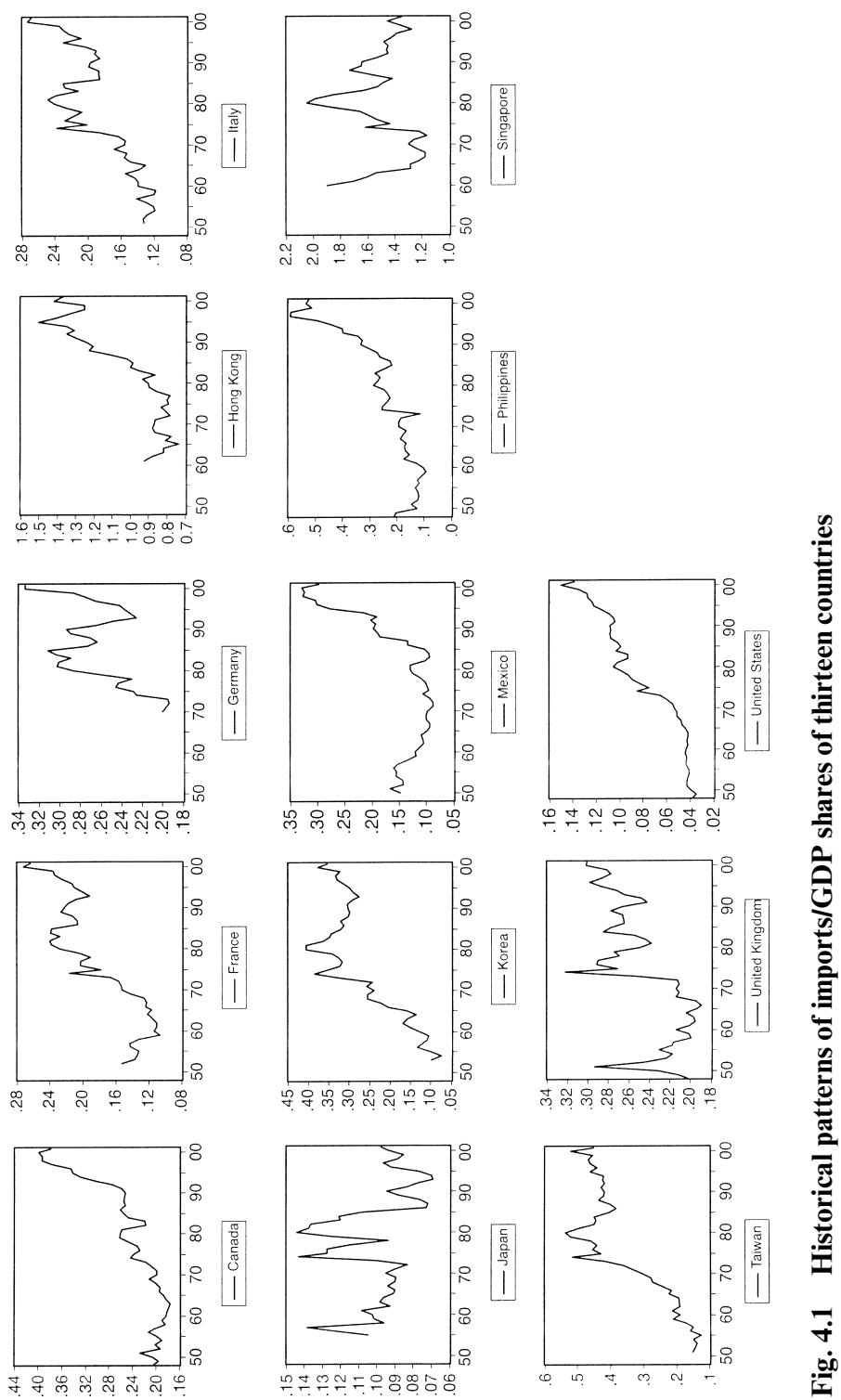

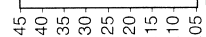

딷ㄷㄷ응ㅇㅇㅇㅇㅇ
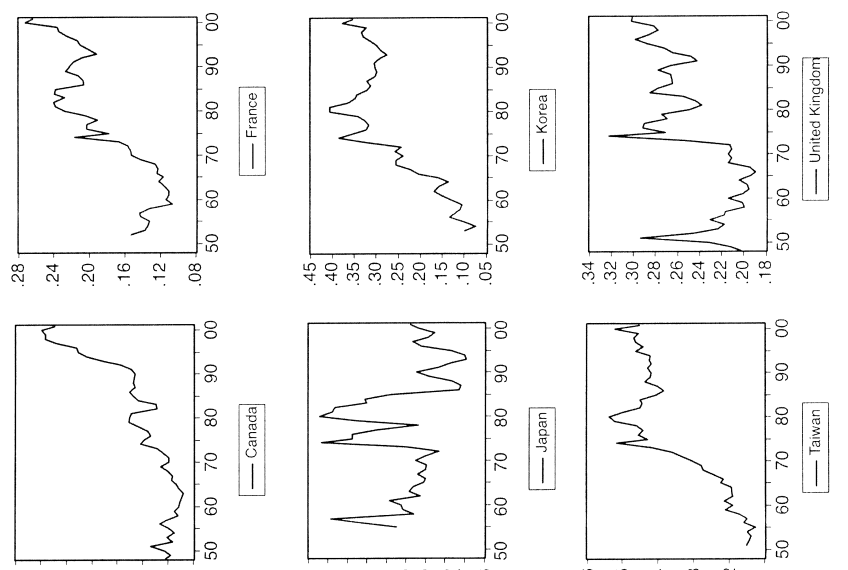

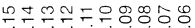

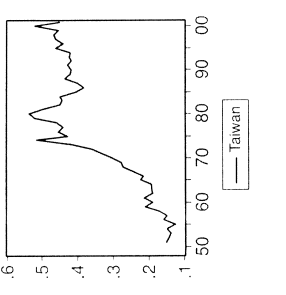




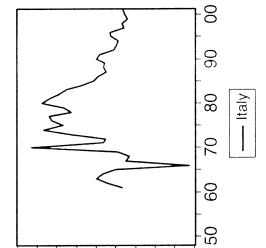

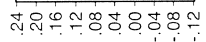

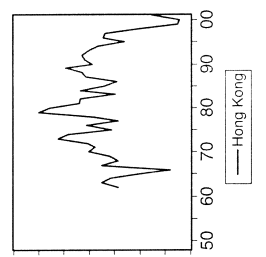

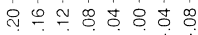

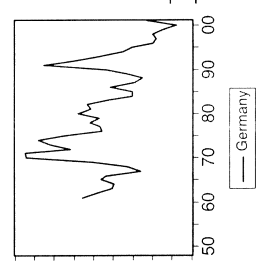

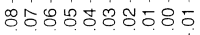

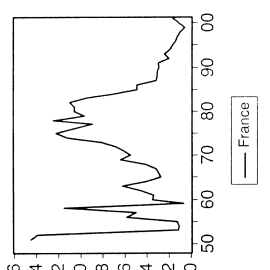

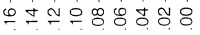

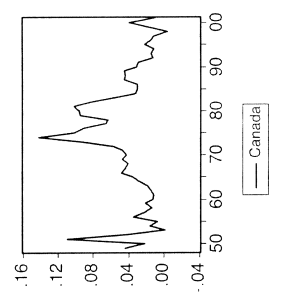

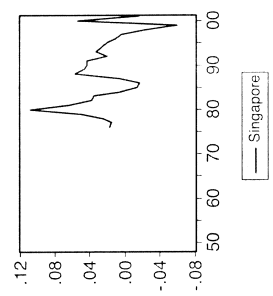
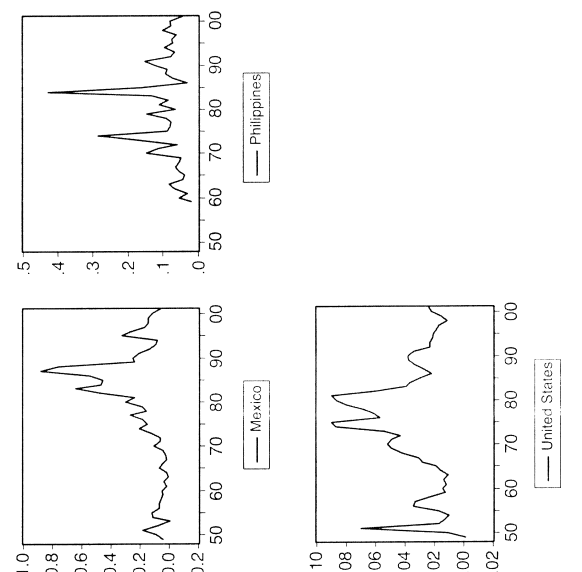

웅 \& 8 \& 8 \%
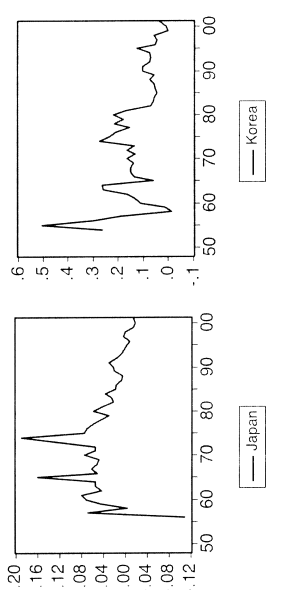
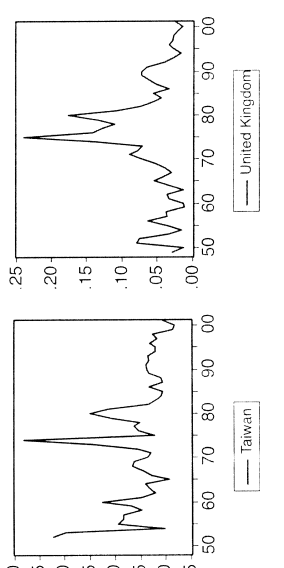

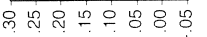

ป⿱艹 
Table 4.1

Related indexes of openness and inflation of thirteen countries (\%)

\begin{tabular}{lrrrr}
\hline & RIM & REX & DPGDP & DCPI \\
\hline Singapore & 152.23 & 119.86 & 3.16 & 3.19 \\
Hong Kong & 89.60 & 98.34 & 6.99 & 7.23 \\
Taiwan & 31.41 & 32.14 & 6.61 & 5.84 \\
Korea & 24.62 & 18.71 & 15.31 & 10.88 \\
Philippines & 19.32 & 17.70 & 9.98 & 7.95 \\
Mexico & 12.25 & 12.49 & 18.64 & 18.20 \\
Germany & 25.54 & 27.02 & 3.88 & 2.76 \\
United Kingdom & 23.67 & 23.10 & 6.58 & 6.36 \\
Canada & 21.50 & 22.09 & 4.85 & 4.51 \\
Italy & 17.30 & 16.29 & 9.55 & 6.96 \\
France & 16.72 & 16.72 & 6.52 & 6.28 \\
Japan & 10.54 & 11.51 & 4.94 & 5.35 \\
United States & 7.16 & 6.78 & 3.82 & 4.02 \\
\hline
\end{tabular}

Source: International Financial Statistics, August 2005, IMF.

Note: In order to compare with the empirical results of Romer (1993), the period of average annual growth rate is from the beginning of each country's variable for which the data is available to 1990 .

Kong and Korea. One of the factors that can be attributed to the low inflation is that in the late 1940s Taiwan experienced a hyperinflation period during which the whole country suffered. ${ }^{4}$ Since then, the Taiwanese government has paid close attention to inflation when conducting monetary or fiscal policy. As for Singapore, from figure 4.2 we can see that in the mid1980s Singapore's economy experienced a three to four year economic recession, which caused a serious deflation. Therefore, if we use the period's averaged inflation rate to represent the inflation condition, a country that experienced deflation naturally would have a lower inflation. However, deflation is not a desire of the Singapore central bank (Monetary Authority of Singapore). A similar situation also existed in the mid 1980s in the Hong Kong economy.

From the above discussion, it can be noted that the extent of one country's openness is determined by geographic condition, traditional culture, and economic development policy, among other factors. The difference of inflation among countries also is determined by many factors that may or may not be related to time consistence theory. If we investigate the relationship between openness and inflation without taking into account these factors, we may obtain a misleading result. By using a period of averaged data that includes a period containing an abnormal event, we may have a wrong description about country's monetary policy, which may seriously distort the interpretation of empirical results.

4. In early 1920s Germany also experienced a hyperinflation episode. 


\subsection{Empirical Analysis of Panel Data}

From figure 4.1 it can be seen that the openness (imports/GDP) of some countries have an obvious increasing trend. If an inverse relationship exists between openness and inflation, the empirical result will be enhanced by using panel data. In this section we analyze the panel data of thirteen countries to verify the relationship. ${ }^{5}$ In order to compare, we adopt the empirical model suggested by Romer (1993) which is of the form:

$$
\pi_{i t}=a_{0}+a_{1} O P E N_{i, t}+a_{2} y_{i, t}+\varepsilon_{i, t}, i=1,2, \ldots, 11 \quad t=1,2, \ldots, n,
$$

where $\pi_{i t}$ is country $i$ 's inflation at period $t$;OPEN $N_{i, t}$ is country $i$ 's openness at period $t$, which is measured by imports/GDP share; and $y_{i, t}$ is country $i$ 's real per capita Gross Domestic Product at period $t$.

Table 4.2 shows the empirical results of panel data regression of thirteen countries. Since we argue that each country has its own characteristics concerning inflation, we include different constant terms for different countries. Column (1) is the model proposed by Romer (1993). It can be seen that in most cases there exist a positive instead of negative sign for openness, though the per capita real output and real growth rate have the right signs. ${ }^{6}$ In addition, this result is robust to different openness, inflation definitions and estimating periods. ${ }^{7}$ If we compare our empirical model with Romer (1993), the only difference is that we take into account different constant terms. In order to check whether it is appropriate to restrict those constant terms to be the same, we do a Wald test for the restriction. The result shows, for all cases, a significant rejection of the null hypothesis that those constants are the same. However, for verifying that imposing the constant constraint will result in different coefficient estimates for openness, we re-estimate our model and show the empirical results in table 4.3. It is surprising to find from the table that if we constrain the constant terms to be the same, the sign on openness is consistent with Romer's argument, that is, openness and inflation have an inverse relationship.

By dividing the sample into developing and developed countries, Romer (1993) found that the inverse relation between openness and inflation is significant in developing countries, but insignificant in developed countries.

5. The data of NIEs and The G7 have different properties. Quarterly data from NIEs are seasonally unadjusted, whereas data from The $\mathrm{G} 7$ is seasonally adjusted. In order to avoid the seasonality problem, we use the annual data to engage in panel estimation.

6. Romer (1993) chose real per capita income to serve as a general measure of development. However, this variable has a different order from other variables such as inflation or imports share. Therefore, we use the change of real GDP as an alternative.

7. In the Romer (1993) paper, he adopted the imports/GDP share to represent a country's openness. In order to check the robustness of empirical results, we have tried various measures of openness, such as exports/GDP share, and (imports + exports)/GDP share, and the empirical results are similar. Though Hsu \& Wu (1993) pointed out that the dynamic structure of the wholesale price index is different from the consumer price index, in this paper we have estimated the case of the wholesale price index and achieved similar results. 


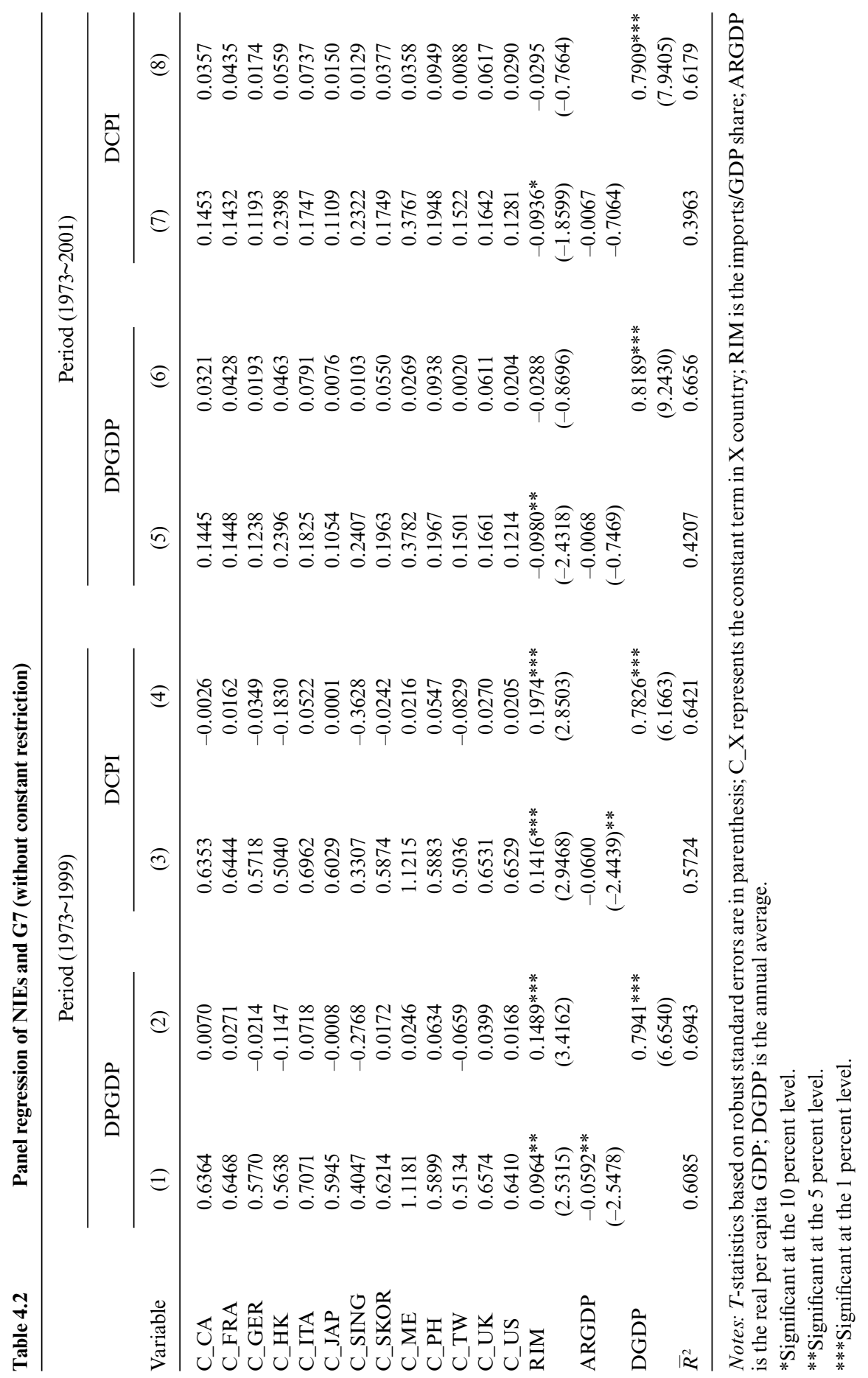




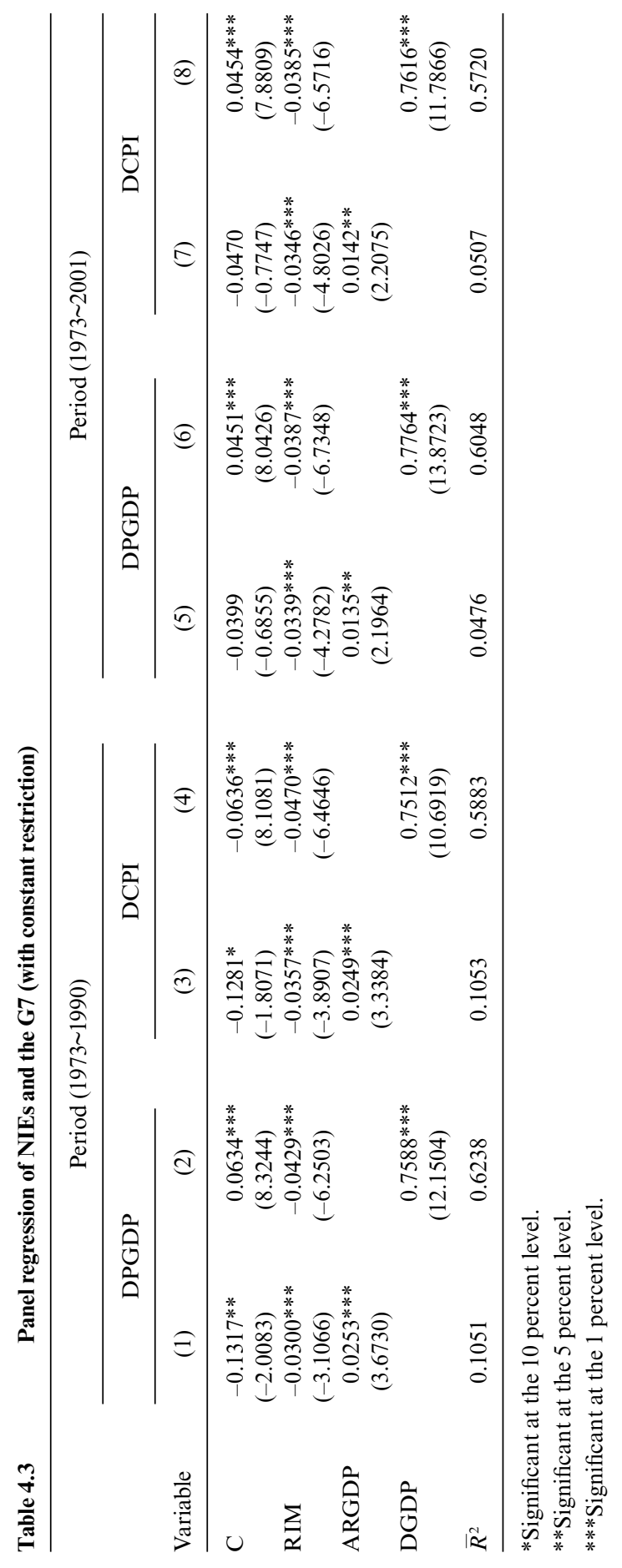


In tables 4.4 and 4.5 we restrict the constant and estimate two different groups, which are NIEs and the G7. From the tables we can see that openness has a significant negative relationship with inflation for NIEs, but have mixed results for the G7. For the period between 1973 and 1990, which is the same sample period used as Romer, the sign on imports/GDP share is positive rather than negative in the case of the G7, and this result is consistent with Romer. However, when we extend our sample period to 2001, the sign on imports share of the G7 become insignificantly different from zeros. To check the robustness of the empirical results with regard to constant restriction, we re-estimate the models and summarize the results in table 4.6 and table 4.7. It can be seen from the tables that the signs on imports share for NIEs are no longer significantly negative. On the contrary, for some cases they have a significant positive sign. As for the G7 countries, the empirical results for those without restriction on constants are similar to the cases with restriction. It can be noted that in the case of included constant terms the coefficients on imports share of the G7 are significantly negative in the extended period. This result may be because a country, like Germany, has a relatively high openness but experiences a sharp declining of inflation due to a weakening economy.

It can be noted from table 4.1 that Singapore is the country with the highest period averaged openness and the lowest period averaged inflation among the Asian 4. If we regard it as an outlier and take it out of the sample, in tables 4.8 and 4.9 it can be shown that even with a constant constraint, in most cases the openness has an insignificant sign. ${ }^{8}$

From the above discussion, it is quite clear that the empirical result of the relationship between openness and inflation is sensitive to the model selection and sample set. Under the more flexible models without constant constraint, or by eliminating the country with special characteristics, Romer's argument is not supported.

\subsection{Time Series Approach}

It can be seen from figure 4.1 that some countries such as Hong Kong, Korea, Taiwan, Canada, France, Italy, and the United States have an upward trend of imports share. Theoretically, they are good examples for verifying the relationship between openness and inflation by using the time series. ${ }^{9}$

From table 4.10 we show the empirical results of time series regression for the inflation model of each individual country. It can be seen that only few cases-France, United Kingdom, and Mexico — show a significant

8. Romer (1993) in footnote 8 pointed out that "re-estimating the regression with Singapore and Lesotho excluded, however, lowers the $t$-statistic on openness only modestly." Nevertheless, our empirical results show a different aspect.

9. We include seasonal dummies into the model whose data is seasonally unadjusted, and only dummies significantly different from zeroes are reported in tables. 


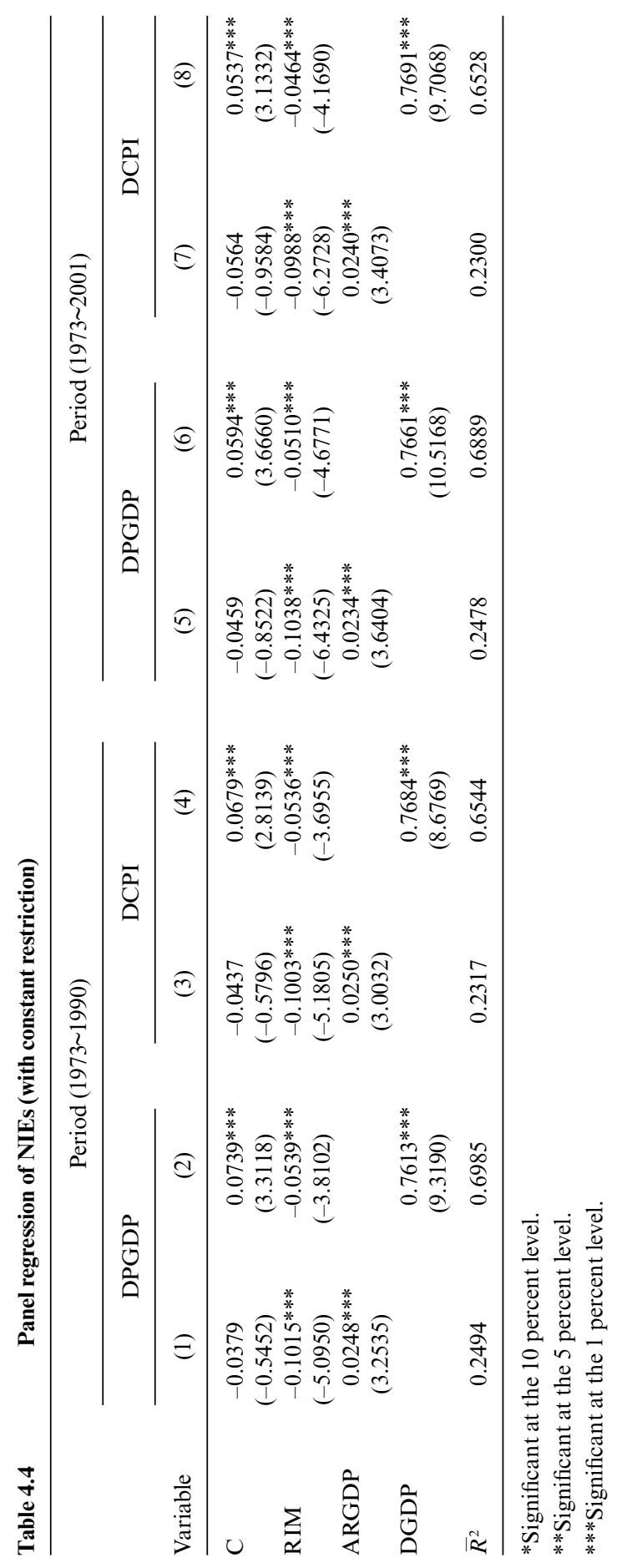




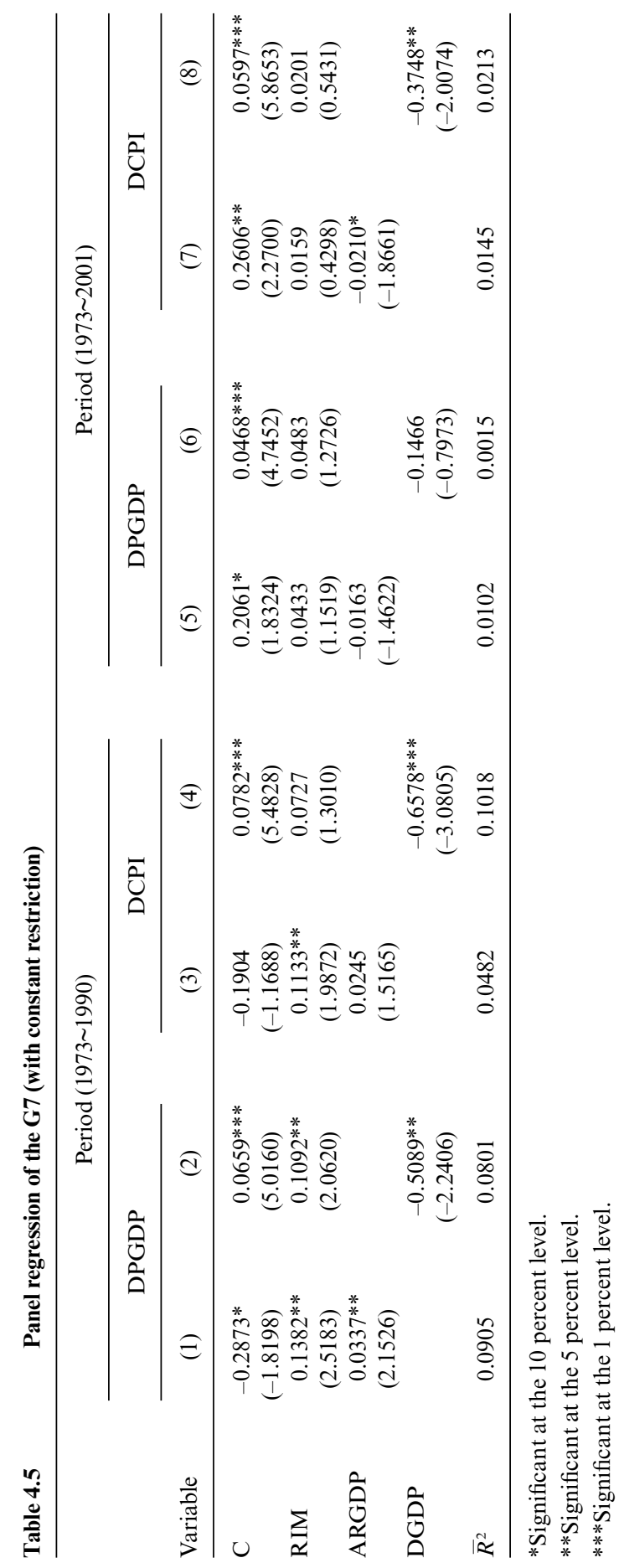




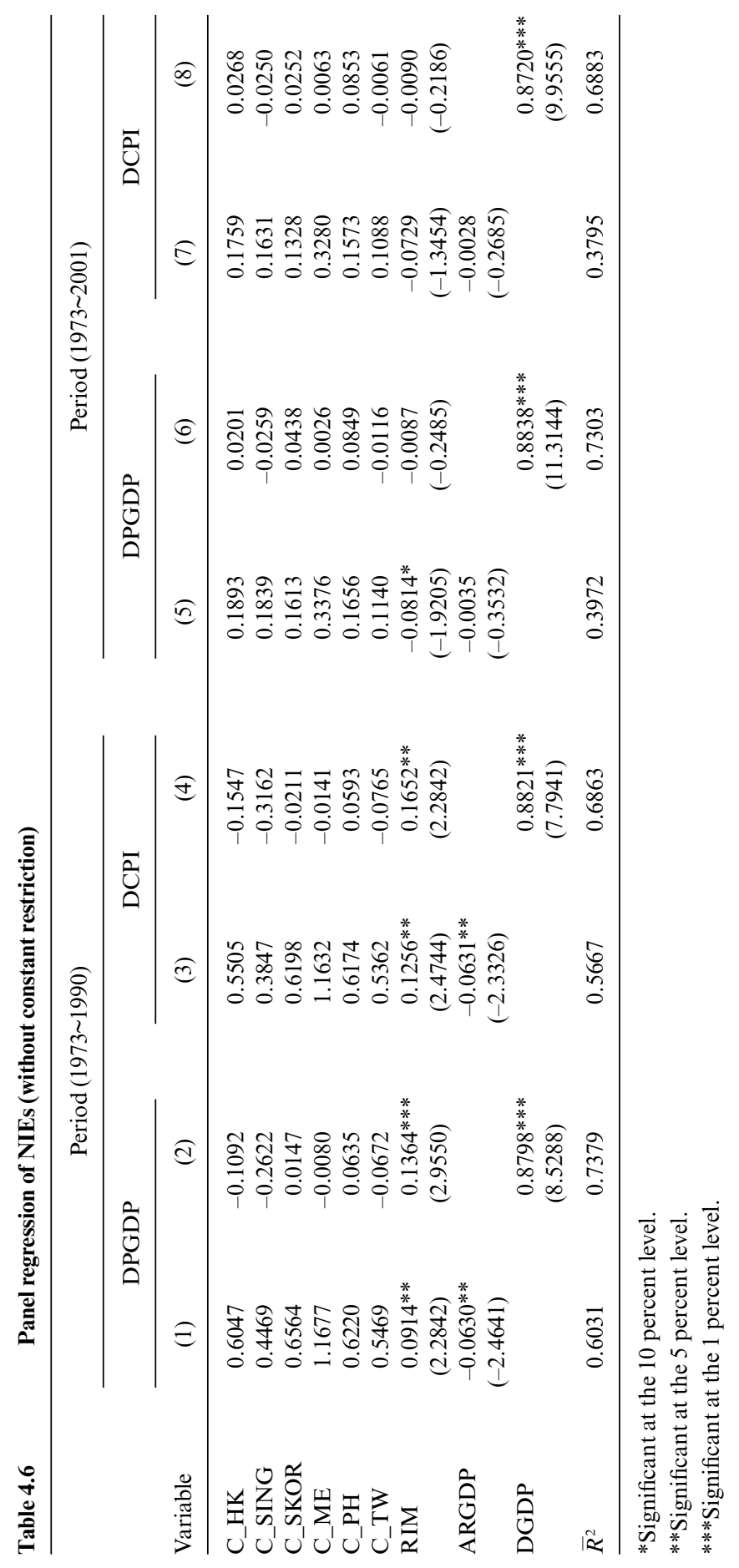




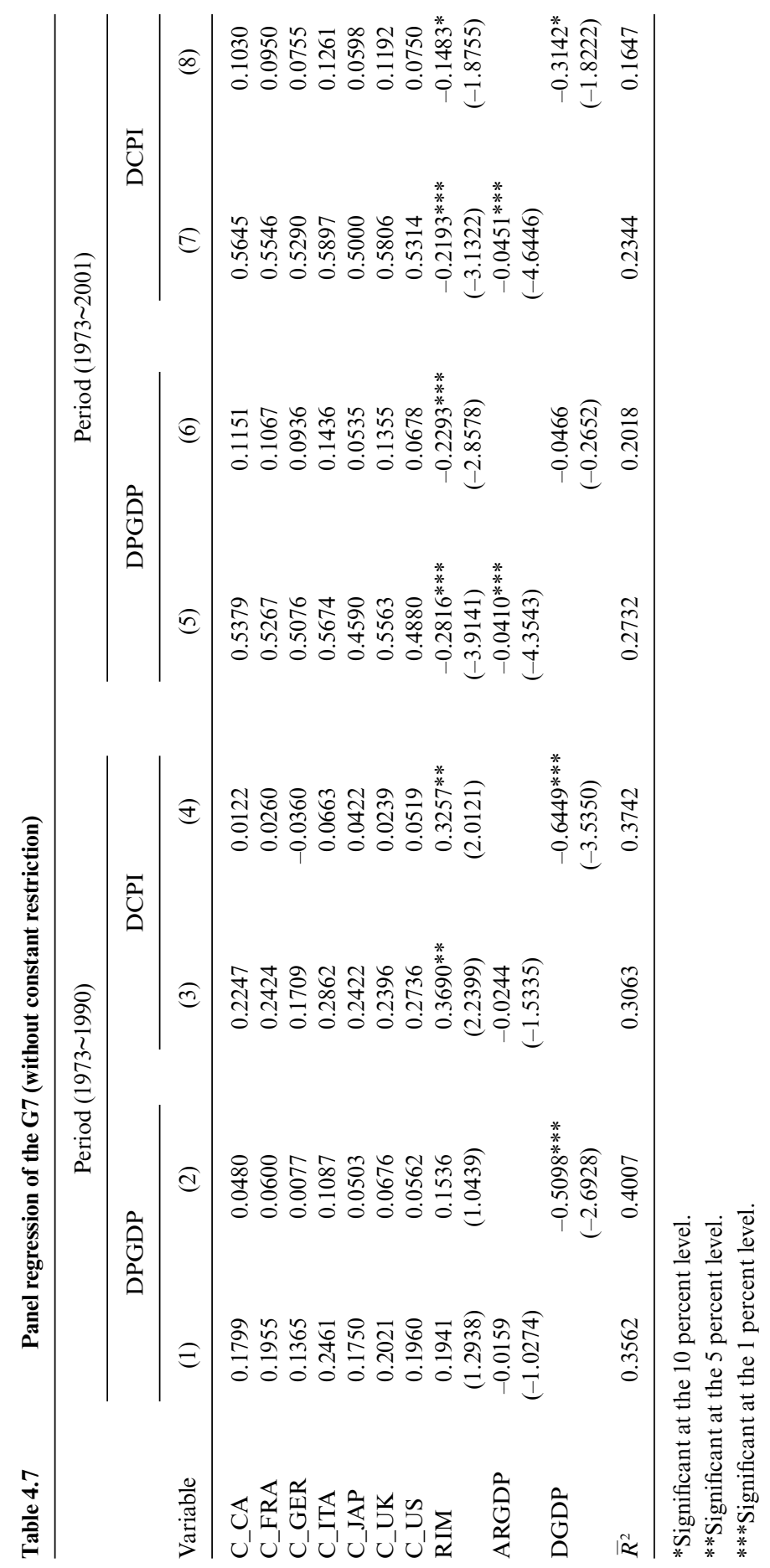




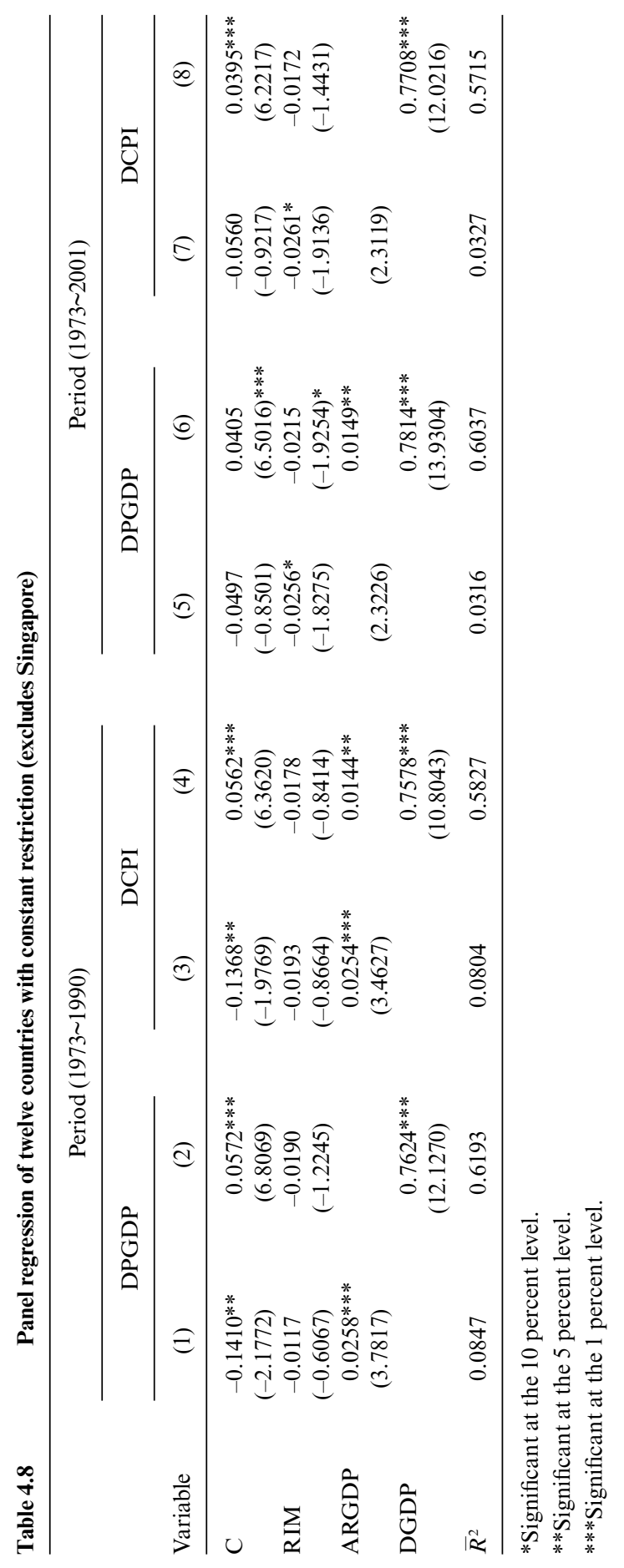




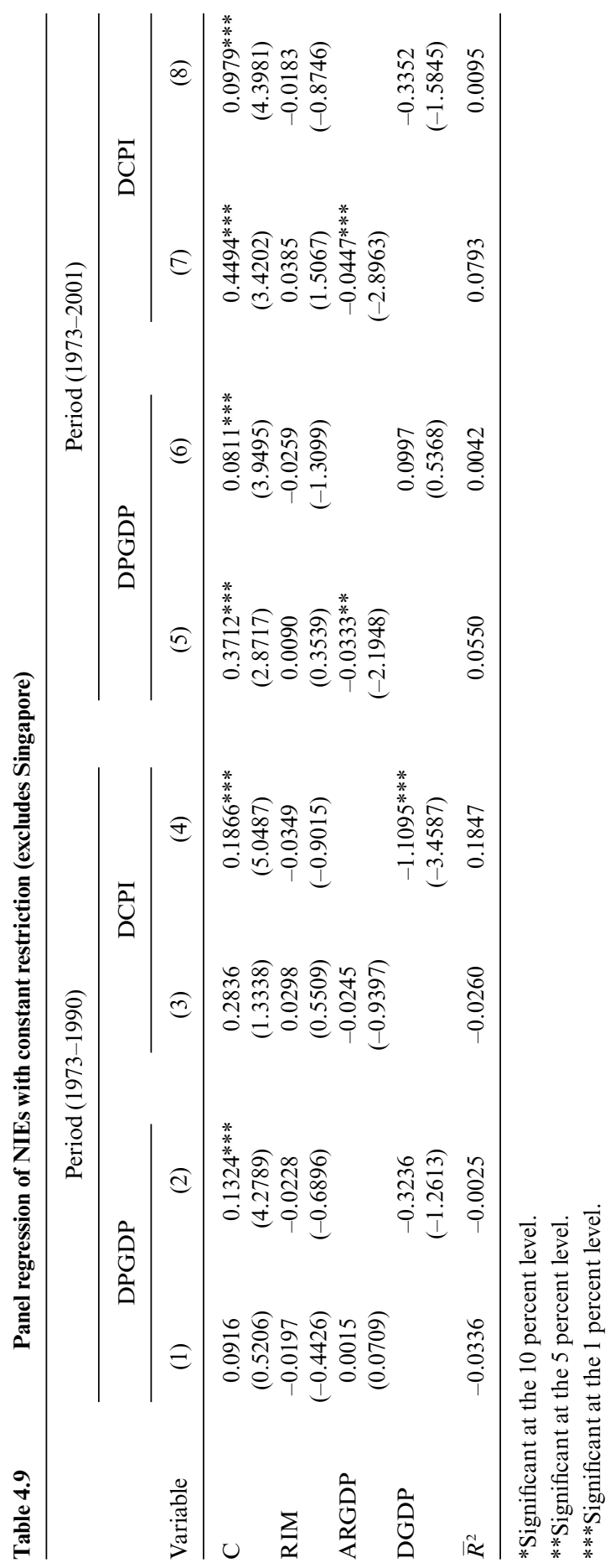




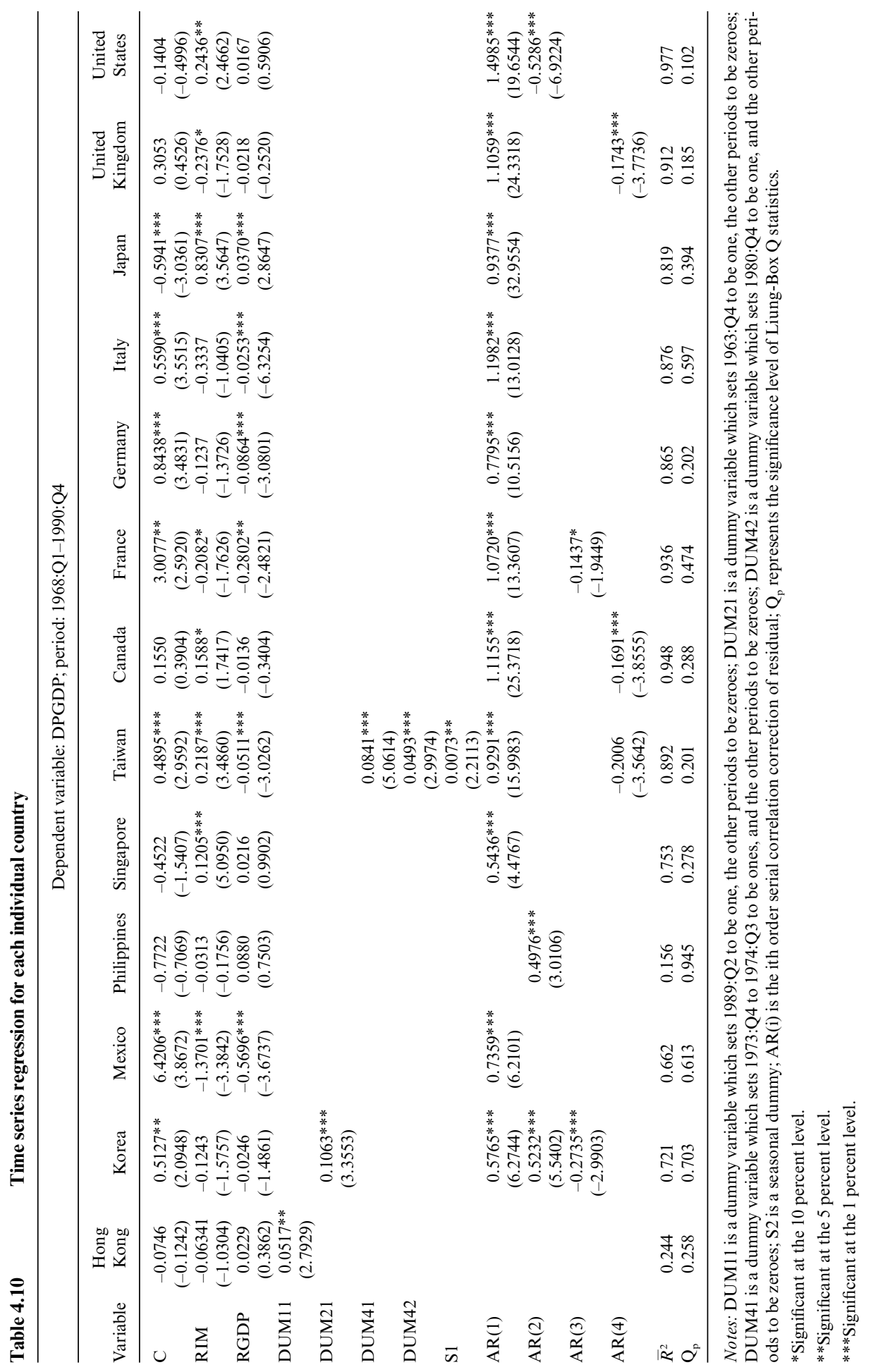


negative sign on imports share. The cases that have a significant positive sign on imports share outnumber those that have a negative sign. Even countries like Canada, Taiwan, and the United States, who have an upward trend of imports share, also have a significant positive sign on imports share. ${ }^{10}$

Although the empirical cross-section model proposed by Romer (1993) may not be an appropriate empirical model for time series approach, it provides an alternative to verify the relationship between inflation and openness. ${ }^{11}$ There is room for improving the time series empirical model, and we believe that different models may have different results. However, under our current framework, we cannot find a strong support for the time consistency theory.

\subsection{Money Supply and Real Output}

Romer (1993) is based on a partial rigidity price model to derive a reverse relationship between openness and inflation. From that model we can also derive a corollary that the effect that a monetary expansion on output is smaller in a more open economy. Since we have quarterly time series, it is convenient for us to verify this hypothesis. In this section, we adopt the VAR model to do the impulse response analysis to examine the impacts of money supply on real output. ${ }^{12}$

It is well-known that the impulse response analysis may be significantly affected by variable ordering. Pesaran and Shin (1988) proposed a procedure to solve the ordering problem. In this section, we follow the approach of Pesaran and Shin (1988) and Lin (2003) to perform the impulse response analysis. Since variables in our VAR model are stationary (first difference of logarithm money supply and logarithm real GDP), it is appropriate for us to ignore the co-integration issues raised by Phillips (1998).

In figure 4.3 we show the impulse response of money growth on real GDP growth according to the order of degree of openness. From the figure it is difficult to find regularity between openness and the impacts of money supply. Singapore has the highest openness, and its money supply also has the most significant impact on real output among the NIEs. Germany has

10. To save space in this paper, we only report the empirical results based on Romer's model in Table 10, and the results are robust to different openness, inflation definitions, and sample periods.

11. Exchange rate is one of the factors that are important determinants of inflation rates. When we incorporate it into the model, the properties of empirical results do not change.

12. Alternatively, we may use transfer function analysis to discuss the dynamic structure between money supply and output. However, in that analysis we have to assume there is no feedback effect between variables, which is inappropriate to our model. See Liu (1987), Liu and Hudak (1985). The VAR impulse response analysis is widely used by researchers to investigate the relationship between malpractice and economy, e.g., Juselius (1998), Oxley (2000), $\mathrm{Wu}$ and $\mathrm{Hu}$ (2000), Morsink and Bayoumi (2001), and Fung (2002). 


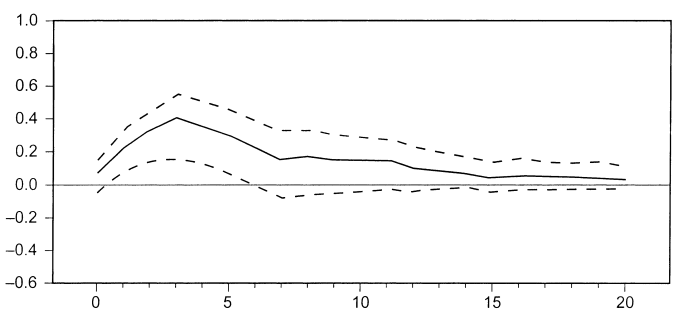

(a) Singapore

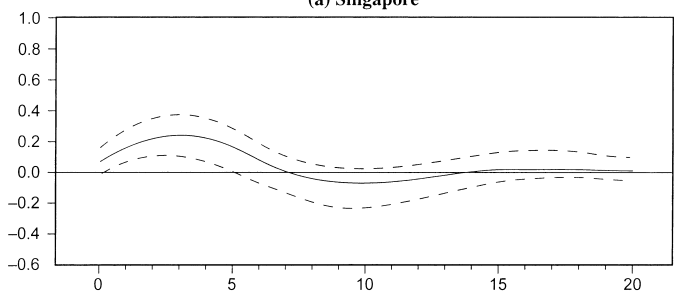

(b) Hong Kong

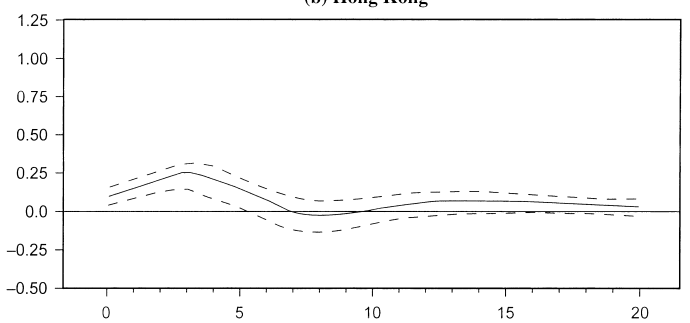

(c) Taiwan

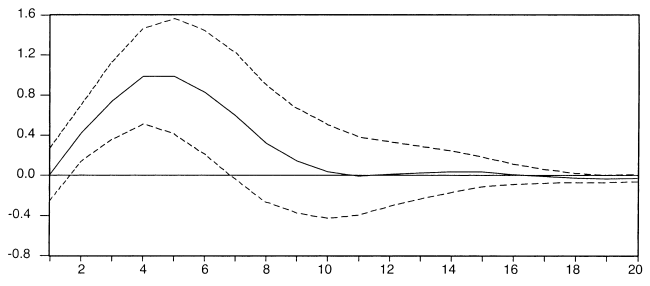

(d) Germany

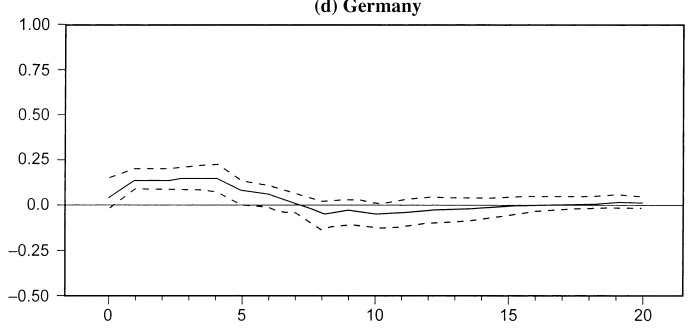

Fig. 4.3 Impulse response of money growth on real GDP growth

Note: (a) Singapore; (b) Hong Kong; (c) Taiwan; (d) Germany; (e) Korea; (f) United Kingdom; (g) Canada; (h) Philippines; (i) Italy; (j) France; (k) Mexico; (l) Japan; (m) United States 
(e) Korea
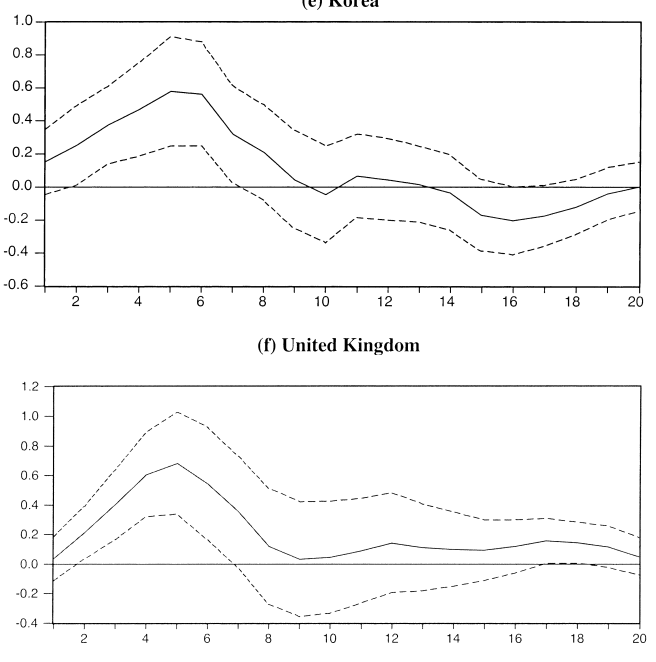

(g) Canada

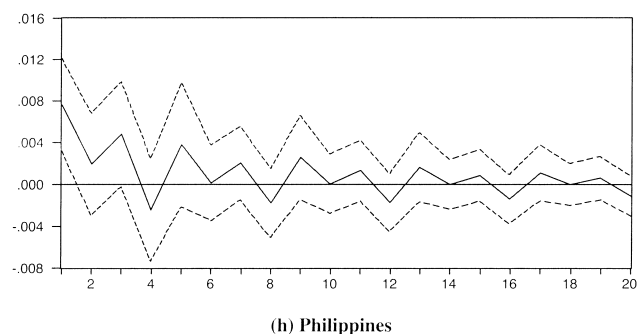

(h) Philippines

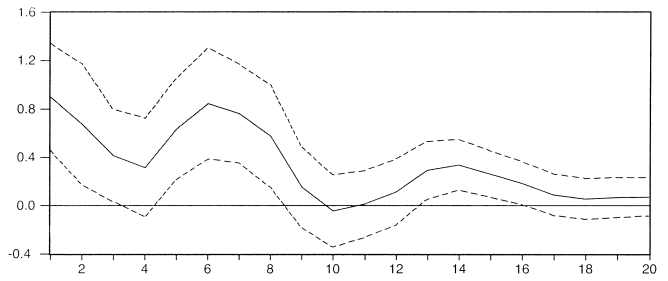

(i) Italy

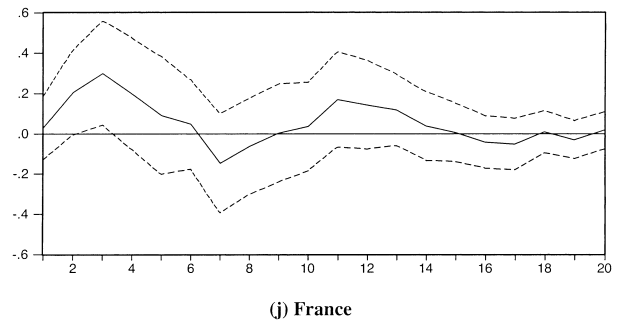

Fig. 4.3 (cont.)

Note: (a) Singapore; (b) Hong Kong; (c) Taiwan; (d) Germany; (e) Korea; (f) United Kingdom; (g) Canada; (h) Philippines; (i) Italy; (j) France; (k) Mexico; (l) Japan; (m) United States 

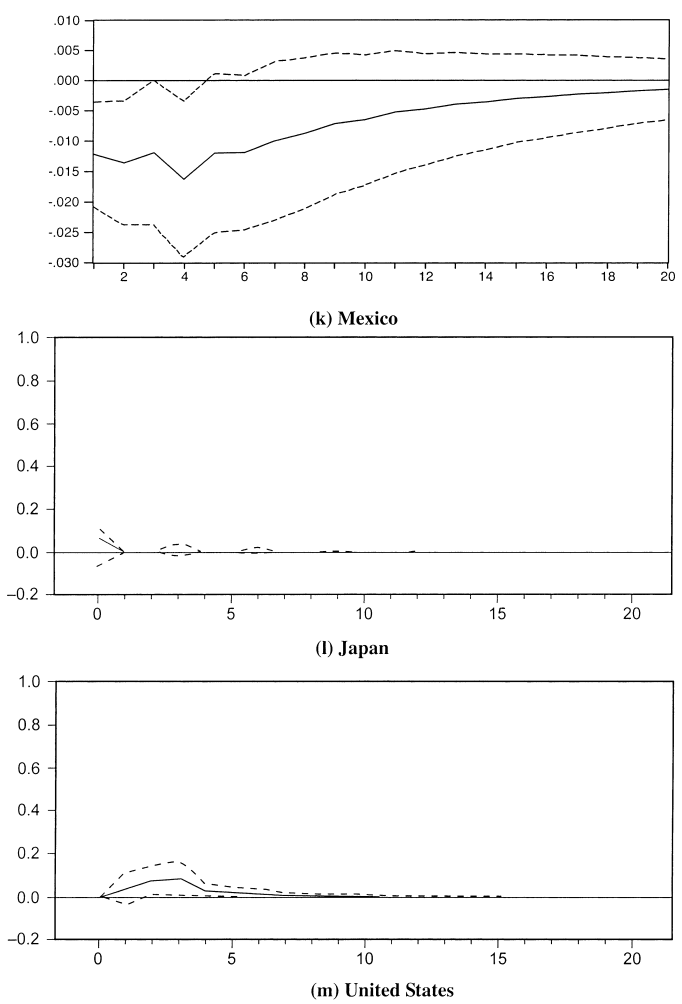

Fig. 4.3 (cont.)

Note: (a) Singapore; (b) Hong Kong; (c) Taiwan; (d) Germany; (e) Korea; (f) United Kingdom; (g) Canada; (h) Philippines; (i) Italy; (j) France; (k) Mexico; (1) Japan; (m) United States

a similar situation as Singapore, which has the highest openness among the G7. However, Germany also has a relatively significant impact of money supply on real output. Interestingly, France, Japan, and the United States, who have a relatively low openness among eleven countries, have a relatively insignificant impact of money supply on real output, which contradicts the corollary derived from Romer (1993).

\subsection{Conclusion}

Romer $(1993,1998)$ argued that the more open economies are, the higher cost for them to adopt a stimulative monetary policy, hence they will choose a more conservative policy than less open economies. Therefore, there exists a reverse relationship between openness and inflation. Since one country's openness is determined by geographic condition, historical experience, and economic development policy, among other variables, inflation can be attributed to factors that may or may not be related to time 
consistency theory. If we investigate the relationship between openness and inflation without taking those factors into account, we may have an inappropriate interpretation of the empirical results. In this paper, we reexamine the relationship by discussing more familiar economies, NIEs and the G7, which can provide us more information about empirical findings.

Our empirical results show that for a panel data set of thirteen countries, models with or without constant constraint give different relationships between openness and inflation. If we restrict the constant terms to be the same, the empirical results are similar to Romer (1993). However, if we relax the restrictions, which are supported by empirical testing, the empirical results do not show a certain relationship between openness and inflation. In addition, leaving out some countries with special structures, the empirical results also change significantly. When we use the time series approach to analyze the relationship between openness and inflation in each individual country, for most cases the negative relationship cannot be supported even in those countries that have an obvious upward trend of imports share. Moreover, we employ a VAR model to check the corollary of Romer (1993) that the affects of money on real output are smaller in a more open economy. From the results of impulse response analyses, we cannot find a regular relationship between openness and the impacts of money supply.

Each country has its own characteristics, including geographic, cultural, and historical background, and through time many factors drive the changing patterns of openness and inflation of each country. It is difficult for a period averaged data to reveal that information, and show a stable regularity between openness and inflation. Though our empirical results are not in accordance with the findings of Romer $(1993,1998)$, they do not mitigate the importance of the time consistency theory. The primary purpose of this paper is to point out that perhaps researchers should pay more attention to the reasons why openness and inflation have different relationships among different countries, rather than searching for a uniform relationship.

\section{References}

Fung, B. S. C. 2002. A VAR analysis of the effects of monetary policy in East Asia. BIS Working Paper no. 119.

Hsu, J. D., and C. S. Wu. 1993. Current prices and policy (in Chinese). Research Report of Research, Development and Evaluation Commission. Taipei, Taiwan: Executive Yuan, pp. 1-151.

Juselius, K. 1998. Changing monetary transmission mechanisms within the EU. Empirical Economics 23 (1): 455-81.

Lane, P. R. 1997. Inflation in open economies. Journal of International Economics 42:327-47. 
Lin, J. L. 2003. An empirical investigating of interest rate policy transmission mechanism and its impacts on macroeconomic and financial system (in Chinese). Quarterly Journal of Central Bank 25 (1): 5-47.

Liu, L. M. 1987. Sales forecasting using multi-equation transfer function models. Journal of Forecasting 6:223-38.

Liu, L. M., and G. B. Hudak. 1985. Unified econometric model building using simulations transfer function equations. In Time series analysis: Theory and practice, vol. 7, ed. O. D. Anderson, 277-88. Amsterdam: Elsevier Science Publishing.

Morsink, J., and Tamim Bayoumi. 2001. A peek inside the black box: The monetary transmission mechanism in Japan. IMF Staff Papers 48 (1): 22-57.

Oxley, L. 2000. Identifying an interest rate transmission mechanism for New Zealand. Australasian Econometric Society Meeting, Auckland, July.

Pesaran, H. H., and Y. Sin. 1988. Generalized impulse response analysis in linear multivariate model. Economic Letters 58:17-29.

Phillips, P. C. B. 1998. Impulse response and forecast error variance asymptotics in nonstationary VARS. Journal of Econometrics 83:21-56.

Romer, D. 1993. Openness and inflation: Theory and evidence. Quarterly Journal of Economics 108:869-903.

Romer, D. 1998. A new assessment of openness and inflation: Reply. Quarterly Journal of Economics 113:649-52.

Temple, J. 2002. Openness, inflation, and the Phillips curve: A puzzle. Journal of Money, Credit and Banking 34 (2): 450-68.

Terra, M. C. T. 1998. Openness and inflation: A new assessment. Quarterly Journal of Economics 113:641-48.

$\mathrm{Wu}, \mathrm{C}$. S., and S. C. Hu. 2000. Interest rates, credit rationing and banking deregulation in Taiwan. Deregulation and Interdependence in the Asia-Pacific Region, ed. T. Ito and A. O. Krueger, 255-76. Chicago: University of Chicago Press.

\section{Comment Peter Blair Henry}

Professors $\mathrm{Wu}$ and Lin have provided us with a useful study of openness and inflation. Previous work documents that openness and inflation are negatively correlated across countries (Romer 1993). Wu and Lin take exception with this result and demonstrate that the relationship uncovered by Romer is not robust. In the context of the Newly Industrialized Economies (NIEs) and the Group of Seven (G7), there is no systematic relationship between openness and inflation. More generally, Wu and Lin argue that there are many pitfalls associated with using purely cross-sectional data to study the relationship between openness and inflation, and implicitly warn us not to do so in future work.

The authors begin very sensibly by taking us through the raw data. This is instructive, because it immediately raises questions about Romer's find-

Peter Blair Henry is professor of economics and Gunn Faculty Scholar at Stanford University, Graduate School of Business, a faculty research associate of the National Bureau of Economic Research, and a Nonresident Senior Fellow of the Brookings Institution. 
ings, at least within this particular subsample. There are four observations in table 4.1 that do not accord with the view that greater openness is associated with lower inflation: (a) Hong Kong is more open than Taiwan but has had higher inflation than Taiwan; (b) The United Kingdom is more open than the United States but has had higher inflation than the United States; (c) France is more open than Japan but has also had higher inflation than Japan; and (d) Both Hong Kong and South Korea are more open than most $\mathrm{G} 7$ countries but have had higher inflation.

Moving beyond the raw data, formal panel regressions also do not show a systematic negative relationship between openness and inflation. Panel data allows the authors to include country-specific dummies to account for sundry differences across countries (culture, geography, etc.) that Romer was not able to account for in his strictly cross-sectional set up. With and without country dummies, $\mathrm{Wu}$ and Lin find little evidence to suggest that openness and inflation are negatively correlated. While the authors succeed in their modest aim of demonstrating the fragility of the relationship between openness and inflations in this sample, I have a few quibbles with what they have done.

First, although I am sympathetic to the general point of the paper, I think that it is a little unfair of the authors to make a direct comparison of their study of 13 countries with the Romer study, which has 114 . With the 13 countries in the $\mathrm{Wu}$ and Lin sample, empirical power is a nontrivial issue, and the question then becomes: is the relationship between openness and inflation really not in the data, or is there simply too much noise to reliably detect its presence?

Second, is this a paper about the time consistency theory of inflation or is it a comparative study of inflation in the NIEs and the G7? If it is the former, then the comments about small sample size in the previous paragraph hold with greater force. If it is a comparative analysis then I would like to know more about the inflation histories of these countries than is conveyed in figure 4.2. For example, is the story behind the fall in inflation in the NIEs similar to that of the great 1980s disinflation that took place in the G7 countries? This kind of institutional focus would add a lot to the paper. The authors convincingly argue that strictly cross-sectional analyses miss important insights conveyed by the heterogeneity of country-specific experiences through time. Indeed, there is much to be learned by reducing sample size and focusing on country experiences. I only wish that the paper would have delivered a bit more in this regard.

Third, I would have liked the paper to be a bit more ambitious. The authors focus exclusively on the time-inconsistency theory of monetary policy that motivated the Romer study. This approach focuses on the insight that in an open economy, policies that stimulate aggregate demand have two offsetting effects. The first effect is that stronger aggregate demand stimulates production and raises national income. The second is that stronger 
aggregate demand also increases imports, which reduces national income. Because the second effect is not present in a closed economy, expansionary monetary policy has a smaller impact on real output in an open economy than it does in a closed one. Therefore, the incentive for the monetary authority to surprise the public with a monetary expansion is lower in an open economy.

This is a perfectly good theory to test, but it seems to me that there are other important mechanisms through which openness may help to maintain low inflation. In particular, an increasingly popular view is that increased integration of goods and labor markets helps to hold down the worldwide level of inflation, because the threat of global competition reduces the pricing power of firms and the bargaining power of workers (Rogoff 2003). Because the countries in this sample are all active participants in the ongoing process of global economic integration, it would seem natural to test whether any of these other channels have any empirical relevance. For instance, instead of just looking at the correlation between consumer-price-and-deflator-based measures of inflation, why not bring wages into the story? Is it the case that wage growth is slower in more open economies, controlling for things like changes in productivity?

\section{References}

Rogoff, K. 2003. Globalization and global disinflation. Federal Reserve Bank of Kansas City Economic Review 88 (4): 45-81.

Romer, D. 1993. Openness and inflation: Theory and evidence. Quarterly Journal of Economics 108 (4): 869-903.

\section{Comment John Simon}

This paper reinvestigates the results of Romer (1993) and suggests that the negative correlation between openness and inflation found by Romer may not be robust. In my comments I would like to focus on a particular difference between the approach of Romer and Wu and Lin - the use of time series data rather than cross sectional data-and its implications for these findings.

To provide a reference point for my comments I consider the data for Australia shown in figure 4C.1. Openness, measured as the ratio of imports to GDP, is strongly trending and rises from a little under 10 percent in the 1960 s to over 20 percent today. Inflation, captured here by the GDP defla-

John Simon is chief manager of the Payments Policy Department of the Reserve Bank of Australia. 


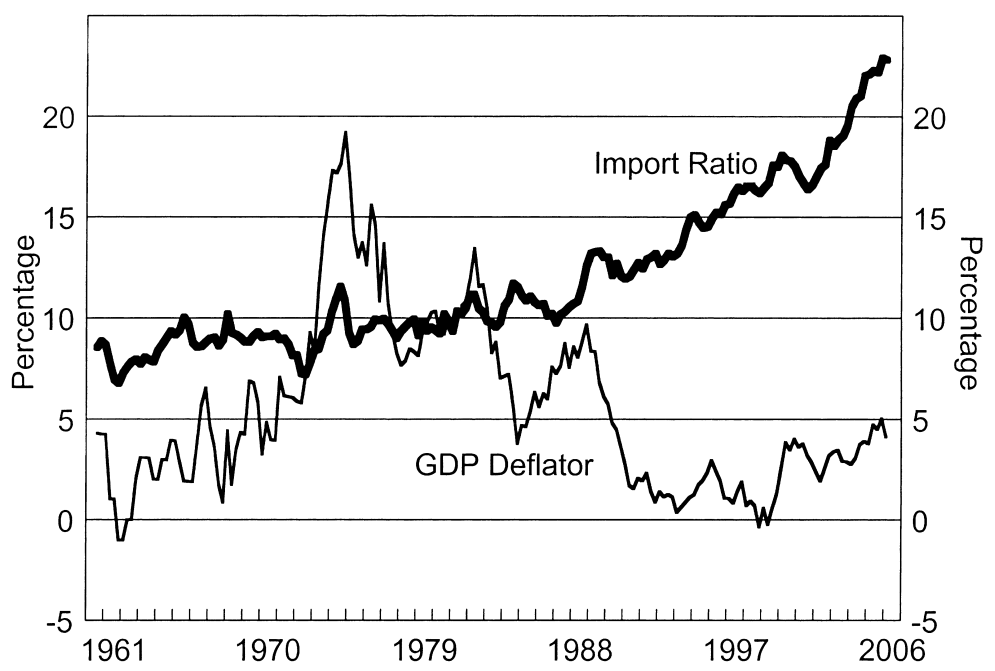

Fig. 4C.1 Inflation and Openness

Source: ABS

tor, was below 5 percent in the 60 s, and rose significantly in the 70 s before returning below 5 percent in the early 90 s. This pattern, if not the specific numbers, is common to many countries. (See figure 4C.1).

The first observation is that time series regressions on this data will have to deal with the integration of the series. Openness is clearly I(1). But there is a question about whether to treat inflation as $\mathrm{I}(1)$ or $\mathrm{I}(0)$ with breaks. Since the return of low inflation in the early 90 s it is $I(0)$. However, when using the full sample its properties are ambiguous, and it can be classified as either $\mathrm{I}(1)$ or $\mathrm{I}(0)$ depending upon the particular test used. Similarly, tests of cointegration between inflation and openness are ambiguous. Although, once again, it is pretty clear that inflation and openness are not cointegrated over the recent low inflation period (primarily because inflation is not integrated). Given this, interpretation of time series regression results on these variables will be problematic.

A further complication to the interpretation of this relationship is the addition of output per capita to the model. This variable is included in both Romer and $\mathrm{Wu}$ and Lin as a control for openness on the argument that richer countries trade more. But from an econometric point of view, the relevant point is that it is a strongly trending series. A long run relationship between inflation and openness could be obtained if openness and output per capita were cointegrated and inflation was I(0), or a more complicated cointegrating relationship between all three variables may exist. Regardless, I think the paper would benefit from careful attention to these issues.

Related to the use of output per capita is the question of whether it is the 
best control for openness. There is a large literature on the expected amount of trade between various countries. And while output per capita is an important variable, it is not the only one used. For example, geographic location has an effect on trade. The appropriate variables to use will be affected by the panel estimation technique chosen; static variables cannot be used in a fixed effects regression. For example, while a country's location does not change, the group of countries it trades with and, thus, its weighted average distance from those countries does. Therefore, as the Asian region has expanded, the center of gravity for many country's trade has also changed.

The second observation is that Australia, along with many other countries, has experienced a fair number of exchange rate and monetary policy regimes over the sample period. Prior to 1973, Australia was in the Bretton Woods arrangement. In Romer's original paper he excluded data from before 1973 to avoid problems created by this arrangement. Wu and Lin also follow this approach for their panel regressions, but not for the individual country regressions in section 4 of the chapter. Following Bretton Woods, Australia used a variety of managed exchange rate regimes before floating the dollar in 1983. Finally, an inflation targeting regime was adopted in the early 1990s. Each of these regimes has implications for the basic Romer hypothesis that, when there is an inability to commit to low inflation outcomes, greater openness ought to be associated with lower inflation. The most significant conceptual problem is with inflation targeting regimes, which have now been adopted by a significant range of countries. An inflation targeting regime presumably involves a credible commitment by the monetary authority to a particular inflation rate. Under such a regime, the relationship posited by Romer should be inoperative. It would be an interesting extension for the paper to investigate this further.

Finally, and most importantly, a question that arises in my mind is whether one would expect to see the Romer relationship between inflation and openness in a country time series in the first place? The basic Barro and Gordon (1983) model used by Romer posits that a central bank has an incentive to generate surprise inflation in the pursuit of higher output growth. Romer extends this by suggesting that the incentive becomes weaker in more open economies and, thus, that lower inflation results. Imagine then, that imports rise in a given country. Is a central bank really going to respond to this arise by producing slightly less surprise inflation that very year? What if the higher imports are a consequence of lower tariffs? Would a central bank really work to offset the inflationary consequences of lower tariffs by generating surprise inflation, albeit less than it usually does?

The first hypothetical question points to the possibility that any relationship will, at best, be present over the longer run and not observable in year-to-year movements in inflation and openness. A related point is that the model emphasized by Romer is static. A consideration of the dynamics 
involved is likely to involve significant complication compared with the cross-sectional model estimated by Romer. The latter questions raise the possibility that inflation and openness may be negatively related for reasons unrelated to the model proposed by Romer - trade has generally been increasing in recent years as trade barriers have gradually been lowered throughout the world. That is, even if the Romer effect were present in the time series data, there is no reason to expect that a time series regression of the two would be able to identify its existence, given the confounding factors likely present in the data.

More conceptually, it seems to me that the Romer model is one that is much more likely to be relevant in explaining the differences between countries than within countries. In part it is because the fundamental model is static, but it also reflects the fact that each country is likely to make its own evaluation of its preferred trade-off between output and inflation (and the plethora of other macroeconomic variables); any variation in those variables is likely to be much more muted than the differences observed across countries. For example, the difference in labor market outcomes between Sweden and the United States is much larger than the changes one would expect to observe over time in either country. In particular, the kind of tradeoffs one would identify within the countries would be very different from those that would emerge in cross country comparisons.

In light of these general considerations, I have a more specific observation about the paper by $\mathrm{Wu}$ and Lin. They emphasize the fixed effects results, but also conduct random effects regressions. An important feature of a fixed effects regression is that it removes any cross country variation and focuses on the time series dimension. Thus, if the Romer result is one that only applies across countries, the lack of results in a fixed effects regression would be expected. In this respect it is particularly interesting that $\mathrm{Wu}$ and Lin find that the Romer result is observed in the random effects panel regression - that is, without country specific dummy variables. This is suggestive of the idea that the Romer effect is a cross-country effect rather than a within country effect.

My final comment is on section 4.5, which introduces a VAR model as an alternative test of the Romer hypothesis. As a central banker, I have had intimate acquaintance with the raw data that is used to generate monetary aggregates. As such, I place very little faith in any empirical work that relies on them. There are sufficient breaks in the series caused by changing categorizations of financial institutions, that any given monetary aggregate can give a misleading impression about actual monetary growth. Furthermore, given the time periods covered by this study encompassed monetary targeting in a number of countries, I think the Lucas critique is very apposite. At a very practical level, one of the consequences of monetary targeting is that money moves to the financial institutions that are not subject to controls. Thus, when banks are subject to lending controls, nonbank fi- 
nancial institutions are very popular. As a result, the targeted variable, say M2, becomes misleading and a broader aggregate needs to be considered. As such, I think the lack of results in section 4.5 cannot be considered particularly conclusive - it could just be that the data are flawed.

To summarize my comments and make some suggestions for further extension of the work in this paper, let me suggest a hypothesis that $\mathrm{Wu}$ and Lin would be well placed to answer. Is the Romer result a reflection of cross sectional institutional differences and country regimes, or is it one that truly applies within countries over time? A further question is whether the result is a reflection of a third factor rather than being a reflection of a direct relationship between inflation and openness? I think the paper already has some intriguing results that point in a particular direction. I would suggest that putting the lack of time series results into the context of the cross sectional results that do work may help to identify what institutional features are relevant for countries that experience higher openness and lower inflation. For example, the work of Terra (1998) identifying high debt countries as the ones that exhibit a relationship between inflation and openness suggests that all three variables may be indicators of a country's institutional inheritance. With this sort of extension, I believe this paper could provide a valuable complement to the existing literature and a deeper understanding of the inflationary process across countries.

\section{References}

Barro, R. J., and D. B. Gordon. 1983. A positive theory of monetary policy in a natural rate model. Journal of Political Economy 9 (4): 589-610.

Romer, D. 1993. Openness and inflation: Theory and evidence. Quarterly Journal of Economics 108:869-903.

Terra, M. C. T. 1998. Openness and inflation: A new assessment. Quarterly Journal of Economics 113:641-48. 